forms of technology to ensure the safest delivery of the intervention.

\section{Duncan Macrae, F.R.C.A.}

Royal Brompton and Harefield NHS Foundation Trust London, United Kingdom

d.macrae@rbht.nhs.uk

Robert C. Tasker, M.D.

Harvard Medical School

Boston, MA
Diana Elbourne, Ph.D.

London School of Hygiene and Tropical Medicine London, United Kingdom

Since publication of their article, the authors report no further potential conflict of interest.

1. Beardsall K, Vanhaesebrouck S, Ogilvy-Stuart AL, et al. Early insulin therapy in very-low-birth-weight infants. N Engl J Med 2008;359:1873-84.

2. Agus MSD, Steil GM, Wypij D, et al. Tight glycemic control versus standard care after pediatric cardiac surgery. N Engl J Med 2012;367:1208-19.

DOI: 10.1056/NEJMc1401343

\title{
Targeted Temperature Management after Cardiac Arrest
}

TO THE EDITOR: Nielsen and coauthors (Dec. 5 issue) ${ }^{1}$ show the importance of avoiding hyperthermia in patients who have had a cardiac arrest. However, if the clinical objective is to improve the neurologic outcome, it is important to define the expected neurologic outcome in individual patients. Studies have shown that the severity of neuronal lesions is dependent on the delay in initiation of cooling after reperfusion. ${ }^{2}$

In the article by Nielsen et al., the studied patients had a median return of spontaneous circulation of 25 minutes, with a wide interquartile range of 18 to 40 in the hypothermic group and 16 to 40 in the normothermic group. In prolonged cardiac arrest, we do not expect that a reduction of neurologic metabolism by hypothermia will have a real effect on already damaged structures.

We should not conclude, on the basis of this trial, that hypothermia is simply an antihyperthermic strategy. Not all cardiac arrests are equal in terms of the time to return of spontaneous circulation. We should identify the subgroups of patients who can benefit from this form of therapy.

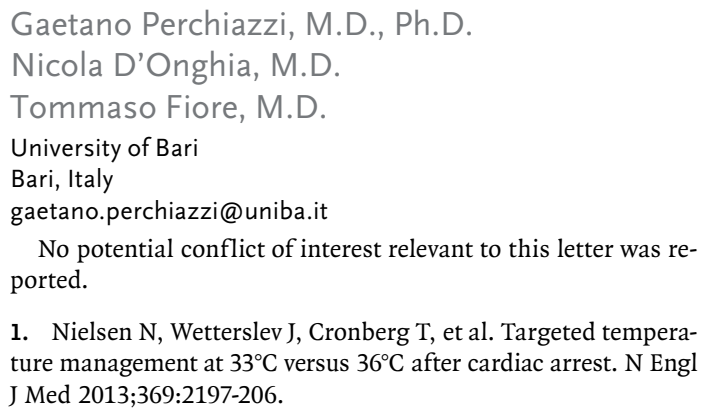

No potential conflict of interest relevant to this letter was reported.

1. Nielsen N, Wetterslev J, Cronberg T, et al. Targeted temperature management at $33^{\circ} \mathrm{C}$ versus $36^{\circ} \mathrm{C}$ after cardiac arrest. $\mathrm{N}$ Engl J Med 2013;369:2197-206.

2. Kuboyama K, Safar P, Radovsky A, Tisherman SA, Stezoski SW, Alexander H. Delay in cooling negates the beneficial effect of mild resuscitative cerebral hypothermia after cardiac arrest in dogs: a prospective, randomized study. Crit Care Med 1993;21: 1348-58.

DOI: $10.1056 /$ NEJMc1401250

TO THE EDITOR: Nielsen et al. confirm that fever should be avoided in resuscitated patients. However, several unanswered questions remain before abandoning therapeutic hypothermia in patients after cardiac arrest. One key issue is the potential benefit of early cooling initiated during cardiopulmonary resuscitation (CPR).

Pathophysiological mechanisms ${ }^{1}$ as well as experimental data suggest a benefit of early cooling, with intra-arrest cooling clearly superior to postresuscitation cooling. ${ }^{2}$ Thus, when moving from very early cooling in the experimental setting to several hours of delay in clinical practice, we might miss the time window for the greatest effectiveness of hypothermia. ${ }^{3}$

Transnasal evaporative cooling can be induced in field conditions during CPR. ${ }^{4}$ The method induces continuous cooling, primarily to the brain, without the hemodynamic side effects recently seen with cold saline. Ongoing and future studies may add important knowledge to this field of research. ${ }^{5}$

Nielsen et al. permitted a time to initiate cooling of 4 hours. We suggest that this time window may be crucial to influence outcome.

Per Nordberg, M.D.

Karolinska Institutet

Stockholm, Sweden

per.nordberg@sodersjukhuset.se 
Fabio Taccone, M.D.

Erasme University Hospital

Brussels, Belgium

Leif Svensson, M.D., Ph.D.

Karolinska Institutet

Stockholm, Sweden

\section{for the PRINCESS Investigators}

No potential conflict of interest relevant to this letter was reported.

1. Froehler MT, Geocadin RG. Hypothermia for neuroprotection after cardiac arrest: mechanisms, clinical trials and patient care. J Neurol Sci 2007;261:118-26.

2. Abella BS, Zhao D, Alvarado J, Hamann K, Vanden Hoek TL, Becker LB. Intra-arrest cooling improves outcomes in a murine cardiac arrest model. Circulation 2004;109:2786-91.

3. Che D, Li L, Kopil CM, Liu Z, Guo W, Neumar RW. Impact of therapeutic hypothermia onset and duration on survival, neurologic function, and neurodegeneration after cardiac arrest. Crit Care Med 2011;39:1423-30.

4. Castrén M, Nordberg P, Svensson L, et al. Intra-arrest transnasal evaporative cooling: a randomized, prehospital, multicenter study (PRINCE: Pre-ROSC IntraNasal Cooling Effectiveness). Circulation 2010;122:729-36.

5. Nordberg P, Taccone FS, Castren $M$, et al. Design of the PRINCESS trial: Pre-hospital Resuscitation Intra-Nasal Cooling Effectiveness Survival Study (PRINCESS). BMC Emerg Med 2013; 13:21.

DOI: 10.1056/NEJMc1401250

TO THE EDITOR: The study by Nielsen et al. revealed no significant difference between hypothermic and near-normothermic treatment groups in patients after cardiac arrest and CPR in terms of their survival and neurologic outcome. This striking finding contradicts the previous understanding of the benefits of this form of therapy, and the next question seems to be whether there is any need to induce hypothermia in these patients.

However, the neurologic evaluation in Nielsen et al. was based on the Cerebral Performance Category (CPC) scale and a modified Rankin scale. These are simple tests devised for assessing patients' independent daily living and are inadequate for assessing cognitive prognosis, when mild cognitive impairment is a real concern in survivors of cardiac arrest. ${ }^{1-3}$ Thus, the findings of Nielsen et al. should not lead to changes in practice before the long-term prognosis of hypothermic versus near-normothermic treatments and the patients' recovery of cognitive function are investigated by means of recent advancements in neurologic assessment. ${ }^{4}$ We ask for more clarification on this topic, which has to precede the decision to "drop the old habit" that may have brought a great deal of benefits to numerous patients during the past decade.

Sungho Oh, Ph.D.

Korea Institute of Machinery and Materials

Daegu, South Korea

Eun-jung Park, M.D.

Sang-cheon Choi, M.D.

Ajou University School of Medicine

Suwon, South Korea

avenue59@ajou.ac.kr

No potential conflict of interest relevant to this letter was reported.

1. Blondin NA, Greer DM. Neurologic prognosis in cardiac arrest patients treated with therapeutic hypothermia. Neurologist 2011;17:241-8.

2. Fugate JE, Moore SA, Knopman DS, et al. Cognitive outcomes of patients undergoing therapeutic hypothermia after cardiac arrest. Neurology 2013;81:40-5.

3. Cronberg T, Lilja G, Rundgren M, Friberg H, Widner $H$. Long-term neurological outcome after cardiac arrest and therapeutic hypothermia. Resuscitation 2009;80:1119-23.

4. Prohl J, Röther J, Kluge S, et al. Prediction of short-term and long-term outcomes after cardiac arrest: a prospective multivariate approach combining biochemical, clinical, electrophysiological, and neuropsychological investigations. Crit Care Med 2007;35:1230-7.

DOI: 10.1056/NEJMc1401250

TO THE EDITOR: Data from the study by Nielsen et al. showing that maintaining temperature at $33^{\circ} \mathrm{C}$ and at $36^{\circ} \mathrm{C}$ have similar benefits in comatose survivors of cardiac arrest originate from patients with an impressively short time to CPR and a higher percentage of bystander-initiated CPR (73\%) than in previous clinical trials (49 to $58 \%)^{1,2}$ Thus, whether such results could be widely applied to communities with a longer time to resuscitation remains to be clarified. Moreover, both midazolam and propofol provide additional neuroprotective effects ${ }^{3}$; however, doses of agents used were not specifically recorded. Finally, no specific guidelines for management of the postresuscitation syndrome were provided, yet it is known that early hemodynamic optimization may improve neurologic outcome after cardiac arrest. ${ }^{4}$ Because patients in the $33^{\circ} \mathrm{C}$ group more frequently had severe cardiovascular impairment than those in the $36^{\circ} \mathrm{C}$ group (76\% vs. $70 \%$ on day 2 and $67 \%$ vs. $54 \%$ on day 3), inadequate organ perfusion may account for potentially harmful effects of a lower target temperature; this was suggested by the higher proportion of deaths before prognostication from cardiac 
causes or multiple organ failure observed in the $33^{\circ} \mathrm{C}$ group.

Fabio Silvio Taccone, M.D.

Antonio Dell'Anna, M.D.

Erasme Hospital

Brussels, Belgium

ftaccone@ulb.ac.be

No potential conflict of interest relevant to this letter was reported.

1. Bernard SA, Gray TW, Buist MD, et al. Treatment of comatose survivors of out-of-hospital cardiac arrest with induced hypothermia. N Engl J Med 2002;346:557-63.

2. The Hypothermia after Cardiac Arrest Study Group. Mild therapeutic hypothermia to improve the neurologic outcome after cardiac arrest. N Engl J Med 2002;346:549-56. [Erratum, N Engl J Med 2002;346:1756.]

3. Harman F, Hasturk AE, Yaman M, et al. Neuroprotective effects of propofol, thiopental, etomidate, and midazolam in fetal rat brain in ischemia-reperfusion model. Childs Nerv Syst 2012;28:1055-62.

4. Tagami T, Hirata K, Takeshige $\mathrm{T}$, et al. Implementation of the fifth link of the chain of survival concept for out-of-hospital cardiac arrest. Circulation 2012;126:589-97.

DOI: 10.1056/NEJMc1401250

TO THE EDITOR: The large, randomized trial by Nielsen et al. showed no significant difference in survival between two strategies of targeted temperature management $\left(33^{\circ} \mathrm{C}\right.$ vs. $\left.36^{\circ} \mathrm{C}\right)$ in comatose survivors of out-of-hospital cardiac arrest and therefore cast doubt on the results of earlier trials that evaluated induced hypothermia in this population. The investigators are to be commended for their rigorous trial with concurrent high rates of coronary angiography and structured, deferred approaches to prognostication and withdrawal of care. Before abandoning $33^{\circ} \mathrm{C}$ as a treatment target, we should consider whether the benefit of this strategy may have been attenuated in this trial.

First, patients in the current study underwent randomization up to 4 hours after cardiac arrest and had a further 4 hours to achieve mean temperatures below $34^{\circ} \mathrm{C} .{ }^{1} \mathrm{~A}$ briefer time to the target temperature after cardiac arrest ${ }^{2}$ or in patients with ST-segment elevation myocardial infarction ${ }^{3}$ may be required to modify reperfusion injury. Second, patients were sedated for 36 hours. Although details were not provided, it is plausible that sedation with propofol may have attenuated the effect of temperature management on the reduction of reperfusion injury. ${ }^{4,5}$

Dion Stub, M.D., Ph.D.

University of Washington

Seattle, WA

dionstub@gmail.com
Dr. Stub reports receiving support from a Victoria Fellowship, a Royal Australasian College of Physicians Fellowship, and an award from the Cardiac Society of Australia and New Zealand. No other potential conflict of interest relevant to this letter was reported.

1. Nielsen N, Wetterslev J, al-Subaie N, et al. Target temperature management after out-of-hospital cardiac arrest: a randomized, parallel-group, assessor-blinded clinical trial - rationale and design. Am Heart J 2012;163:541-8.

2. Mooney MR, Unger BT, Boland LL, et al. Therapeutic hypothermia after out-of-hospital cardiac arrest: evaluation of a regional system to increase access to cooling. Circulation 2011; 124:206-14.

3. Erlinge D, Götberg M, Grines C, et al. A pooled analysis of the effect of endovascular cooling on infarct size in patients with ST-elevation myocardial infarction. EuroIntervention 2013; 8:1435-40

4. Kottenberg E, Thielmann M, Bergmann L, et al. Protection by remote ischemic preconditioning during coronary artery bypass graft surgery with isoflurane but not propofol - a clinical trial. Acta Anaesthesiol Scand 2012;56:30-8.

5. Dahlbacka S, Mäkelä J, Kaakinen T, et al. Propofol is associated with impaired brain metabolism during hypothermic circulatory arrest: an experimental microdialysis study. Heart Surg Forum 2006;9:E710-E718.

DOI: 10.1056/NEJMc1401250

TO THE EDITOR: Nielsen and collaborators report that therapeutic hypothermia $\left(33^{\circ} \mathrm{C}\right)$ conferred no outcome benefits after cardiac arrest, as compared with strict fever control. This directly contradicts the findings of two randomized, controlled trials previously published in the Journal and other data supporting the use of therapeutic hypothermia after hypoxemic injury. ${ }^{1-3}$ How do we explain this? Should current guidelines be changed? The current study is large and well conducted but has potential limitations. One is a rapid rate of rewarming, from $33^{\circ} \mathrm{C}$ to $36^{\circ} \mathrm{C}$ in 6 hours - a much faster rate than in previous trials. Rapid warming is harmful and can negate the benefits of therapeutic hypothermia. ${ }^{4,5}$ In addition, were all consecutive patients with cardiac arrest and return of spontaneous circulation screened for this study, or did physicians preassess potential eligibility? Participating centers routinely used therapeutic hypothermia before this study and continued to treat nonstudy patients with it. Physicians could have subconsciously selected patients with potential benefit for "routine" therapeutic hypothermia rather than refer for screening. The study enrolled an average of only one patient per center per month, possibly indicating preselection.

These results could be misconstrued to advocate abandoning temperature management after cardiac arrest altogether. We agree with the au- 
thors that the question should be what temperature to maintain, not whether temperature control is needed.

Joseph Varon, M.D.

University General Hospital

Houston, TX

\section{Kees Polderman, M.D.}

University of Pittsburgh Medical Center

Pittsburgh, PA

k.polderman@tip.nl

No potential conflict of interest relevant to this letter was reported.

1. Varon J, Acosta P. Therapeutic hypothermia: past, present, and future. Chest 2008;133:1267-74.

2. Polderman $\mathrm{KH}$. Induced hypothermia and fever control for prevention and treatment of neurological injuries. Lancet 2008; 371:1955-69.

3. The Hypothermia after Cardiac Arrest Study Group. Mild therapeutic hypothermia to improve the neurologic outcome after cardiac arrest. N Engl J Med 2002;346:549-56. [Erratum, N Engl J Med 2002;346:1756.]

4. Polderman KH. Mechanisms of action, physiological effects, and complications of hypothermia. Crit Care Med 2009;37:Suppl: S186-S202.

5. Polderman $\mathrm{KH}$, Herold I. Therapeutic hypothermia and controlled normothermia in the intensive care unit: practical considerations, side effects, and cooling methods. Crit Care Med 2009;37:1101-20.

DOI: $10.1056 /$ NEJMc1401250

TO THE EDITOR: With regard to the editorial accompanying the article by Nielsen and colleagues: we reflect on a key assertion that, "In contrast to a decade ago, one half instead of one third of patients with return of spontaneous circulation after CPR can expect to survive hospitalization." In fact, in 2002, the Hypothermia after Cardiac Arrest Study Group ${ }^{2}$ reported a hospital mortality of 43\% (119 of 275 participants). The investigators participating in the Target Temperature Management $33^{\circ} \mathrm{C}$ versus $36^{\circ} \mathrm{C}$ after Out-ofHospital Cardiac Arrest (TTM) trial now report a nearly identical hospital mortality of 44\% (411 of 939 participants).

Using the Australian and New Zealand Intensive Care Society Adult Patient Database (ANZICS APD), which includes data on more than 1.4 million intensive care unit (ICU) admissions and more than 17,000 cardiac arrests, we determined the hospital mortality among patients with out-of-hospital cardiac arrest in Australia and New Zealand from 2003 to 2012. We found a hospital mortality of 61\% in 2003 and $56 \%$ in 2012 and an ICU mortality of $46 \%$ in

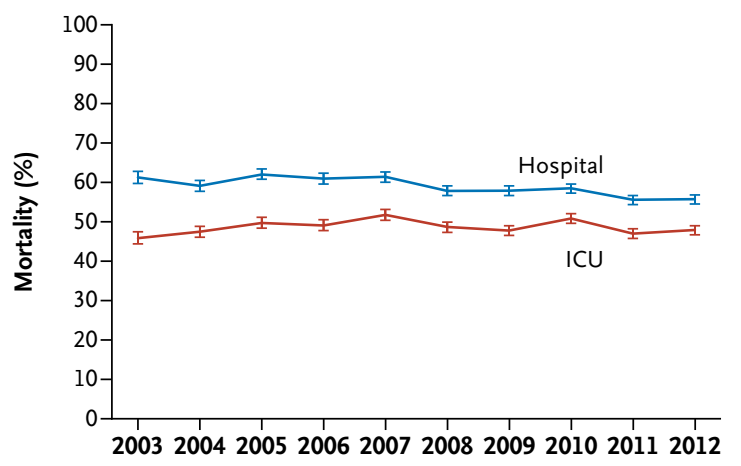

$\begin{array}{lllllllllll}\text { No. of Hospital Deaths } & 665 & 752 & 852 & 802 & 863 & 905 & 947 & 1041 & 1017 & 1019\end{array}$ $\begin{array}{lllllllllll}\text { No. of ICU Deaths } & 489 & 592 & 676 & 644 & 711 & 733 & 774 & 888 & 851 & 872\end{array}$

Figure 1. Hospital and ICU Mortality, 2003-2012.

Shown are hospital and ICU mortality among patients with cardiac arrest who were admitted to ICUs in Australia and New Zealand between 2003 and 2012. I bars indicate $95 \%$ confidence intervals. Data are from the Australian and New Zealand Intensive Care Society Adult Patient Database.

2003 and 48\% in 2012 (Fig. 1). These findings and those mentioned above indicate that hospital mortality in Australia and New Zealand and in the European trial sites has not improved over time. Investigators must now seek new therapeutic interventions that protect the brain and improve mortality and neurologic outcomes after out-of-hospital cardiac arrest. ${ }^{3}$

Glenn M. Eastwood, Ph.D.

Austin Hospital

Melbourne, VIC, Australia

glenn.eastwood@austin.org.au

Michael Bailey, Ph.D.

Rinaldo Bellomo, M.D.

Monash University

Melbourne, VIC, Australia

No potential conflict of interest relevant to this letter was reported.

1. Rittenberger JC, Callaway CW. Temperature management and modern post-cardiac arrest care. N Engl J Med 2013;369: 2262-3.

2. The Hypothermia after Cardiac Arrest Study Group. Mild therapeutic hypothermia to improve the neurologic outcome after cardiac arrest. N Engl J Med 2002;346:549-56. [Erratum, N Engl J Med 2002;346:1756.]

3. Schneider AG, Eastwood GM, Bellomo R, et al. Arterial carbon dioxide tension and outcome in patients admitted to the intensive care unit after cardiac arrest. Resuscitation 2013;84: $927-34$.

DOI: $10.1056 / N E J M c 1401250$ 
DR. Nielsen AND Colleagues Reply: Perchiazzi et al., Nordberg et al., and Stub suggest that a delay in the initiation of temperature management might influence outcome. The window of 240 minutes from return of spontaneous circulation to randomization was based on a study of data from the Hypothermia Network Registry, in which there was no association between time to the initiation of temperature management and 6-month neurologic outcome. ${ }^{1}$ Other large observational studies have given similar signals. ${ }^{2}$ Data from a recent randomized trial showed that early initiation of temperature management does not improve outcome. ${ }^{3}$ Intra-arrest cooling is, however, compelling, and we look forward to results from ongoing trials.

Perchiazzi et al. call for subgroup analyses to elucidate which patients might benefit from one of the interventions. The forest plot in Figure S2 in the Supplementary Appendix (available with the full text of our article at NEJM.org) indicates a homogeneous intervention effect in five predefined subgroups. Further multivariate analysis may give signals in any direction, but we would not recommend basing practice on inferences that at best could be hypothesis-generating.

Oh and colleagues ask for more detailed neurologic assessment at follow-up, and we agree that the CPC scale and the modified Rankin scale represent crude measures. However, the CPC scale was used in trials introducing temperature management in clinical practice. Data from more detailed assessment were collected but have not yet been published. ${ }^{4}$ Survival being the primary outcome, it is important to acknowledge that the TTM trial was not powered to conclusively assess these measures.

Taccone and Dell'Anna comment on the high rate of bystander-initiated CPR in the TTM trial. During the past decade, there has been a continuous rise in bystander-initiated CPR, with positive consequences on overall outcome. ${ }^{5}$ The time to bystander-initiated CPR is naturally relevant only for patients receiving such help and should be short. The time to bystander-initiated CPR was, to our knowledge, not reported in earlier trials on temperature management.

In response to Varon and Polderman: we confirm that sites consecutively screened all patients meeting inclusion criteria and randomly assigned every patient not meeting exclusion criteria. The baseline characteristics, active care $(60 \%$ early angiography and 40\% coronary intervention), and survival rates strongly contradict a selection of patients with a presumed poor outcome.

Whether goal-directed changes in post-cardiac arrest care, sedatives, or the rewarming rate influence outcome is to our knowledge unknown and remains to be investigated in future randomized clinical trials.

We disagree that our trial showed a benefit of avoiding fever; to do so, a no-intervention group would have been necessary. That said, we definitely would not advocate abandoning any temperature management on the basis of the results of the TTM trial.

Niklas Nielsen, M.D., Ph.D.

Helsingborg Hospital

Helsingborg, Sweden

niklas.nielsen@telia.com

Jørn Wetterslev, M.D., Ph.D.

Copenhagen Trial Unit

Copenhagen, Denmark

Hans Friberg, M.D., Ph.D.

Skåne University Hospital

Lund, Sweden

\section{for the TTM Trial Steering Group}

Since publication of their article, the authors report no further potential conflict of interest.

1. Nielsen N, Hovdenes J, Nilsson F, et al. Outcome, timing and adverse events in therapeutic hypothermia after out-of-hospital cardiac arrest. Acta Anaesthesiol Scand 2009;53:926-34.

2. Haugk M, Testori C, Sterz F, et al. Relationship between time to target temperature and outcome in patients treated with therapeutic hypothermia after cardiac arrest. Crit Care 2011;15:R101. 3. Kim F, Nichol G, Maynard C, et al. Effect of prehospital induction of mild hypothermia on survival and neurological status among adults with cardiac arrest: a randomized clinical trial. JAMA 2014;311:45-52.

4. Nielsen N, Wetterslev J, al-Subaie N, et al. Target temperature management after out-of-hospital cardiac arrest: a randomized, parallel-group, assessor-blinded clinical trial - rationale and design. Am Heart J 2012;163:541-8.

5. Adielsson A, Hollenberg J, Karlsson T, et al. Increase in survival and bystander CPR in out-of-hospital shockable arrhythmia: bystander CPR and female gender are predictors of improved outcome. Experiences from Sweden in an 18-year perspective. Heart 2011;97:1391-6.

DOI: $10.1056 /$ NEJMc1401250

THE EDITORIALISTS REPLY: The data from ANZICS APD are a welcome addition to the longitudinal data on survival after cardiac arrest. We urge three points of caution regarding interpretation of these data. First, we wonder whether partici- 
pating ICUs adopted the use of a standard care plan including temperature management soon after the seminal articles, ${ }^{1,2}$ making the excellent survival rates depicted in this graph representative of the "temperature-management era." Second, the relevant comparison group for baseline survival from the Hypothermia after Cardiac Arrest Study Group trial ${ }^{1}$ is the control group, which received no regimented care with respect to temperature management. Although control patients were highly selected from a group with a high likelihood of survival, hospital mortality was $50 \%$ (69 of 138 patients), substantially higher than the hospital mortality of 44\% (411 of 939 patients) in the TTM trial involving less selected patients. Third, if the ANZICS APD includes patients admitted to the ICU, it may not capture deaths that occur in the emergency department or during pre-ICU procedures. Despite this limitation, we do appreciate a modest decline in hospital deaths over the decade from more than $60 \%$ to its current level.

Jon C. Rittenberger, M.D.

Clifton W. Callaway, M.D., Ph.D.

University of Pittsburgh

Pittsburgh, PA

Since publication of their editorial, the authors report no further potential conflict of interest.

1. The Hypothermia after Cardiac Arrest Study Group. Mild therapeutic hypothermia to improve the neurologic outcome after cardiac arrest. N Engl J Med 2002;346:549-56. [Erratum, N Engl J Med 2002;346:1756.]

2. Bernard SA, Gray TW, Buist MD, et al. Treatment of comatose survivors of out-of-hospital cardiac arrest with induced hypothermia. N Engl J Med 2002;346:557-63.

DOI: 10.1056/NEJMc1401250

\section{BMI and Mortality among Adults with Incident Type 2 Diabetes}

TO THE EDITOR: Tobias et al. (Jan. 16 issue) ${ }^{1}$ found no evidence of lower mortality among obese patients with incident type 2 diabetes, as compared with their normal-weight counterparts. An "obesity paradox" (i.e., an association between obesity and reduced mortality) had been reported, in particular in patient populations with a short survival time, whereas obesity by its nature is a risk factor for increased long-term mortality. Our earlier results show that short follow-up and the advanced age of populations with chronic diseases are major limitations of such studies: over short periods, a high body-mass index (BMI) was not associated with increased mortality among patients with end-stage renal disease, but it was also not associated with increased mortality in the general population of equal age. ${ }^{2}$ Moreover, different underlying causes of the disease and coexisting illnesses impede a valid comparison between patients with a high BMI and those with a low BMI. Because of these limitations, it is not possible to translate such observations into causal interpretations - for example, to advise a high body weight in these patients. The findings by Tobias et al. are a timely reminder of the many biases that need to be taken into account before a causal interpretation of population data is possible.

\author{
Renée de Mutsert, Ph.D. \\ Michiel F. Nijhoff, M.D. \\ Jan P. Vandenbroucke, M.D., Ph.D. \\ Leiden University Medical Center \\ Leiden, the Netherlands \\ r.de_mutsert@lumc.nl
}

No potential conflict of interest relevant to this letter was reported.

1. Tobias DK, Pan A, Jackson CL, et al. Body-mass index and mortality among adults with incident type 2 diabetes. $\mathrm{N}$ Engl J Med 2014;370:233-44.

2. de Mutsert R, Snijder MB, van der Sman-de Beer F, et al. Association between body mass index and mortality is similar in the hemodialysis population and the general population at high age and equal duration of follow-up. J Am Soc Nephrol 2007;18:967-74.

DOI: 10.1056/NEJMc1401876

TO THE EDITOR: Although Carnethon et al. ${ }^{1}$ found a better prognosis in obese patients with type 2 diabetes as compared with patients of "normal" weight, Tobias and colleagues did not find an obesity paradox. They explained that prior analyses were limited by short follow-up, a small number of deaths, and a lack of data on smoking or undiagnosed diseases.

We are concerned, however, that neither study mentioned above accounted for fitness, especially because obese but fit persons with type 2 diabetes have a considerably better prognosis 